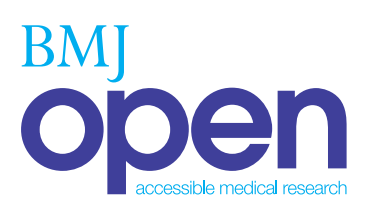

\title{
The effect of MELatOnin on Depression, anxietY, cognitive function and sleep disturbances in patients with breast cancer. The MELODY trial: protocol for a randomised, placebo-controlled, double-blinded trial
}

To cite: Hansen MV, Madsen MT, Hageman I, et al. The effect of MELatOnin on Depression, anxietY, cognitive function and sleep disturbances in patients with breast cancer. The MELODY trial: protocol for a randomised, placebo-controlled, double-blinded trial. BMJ Open 2012;2:e000647. doi:10.1136/ bmjopen-2011-000647

- Prepublication history for this paper is available online. To view these files please visit the journal online (http:// bmjopen.bmj.com).

Received 18 November 2011 Accepted 19 December 2011

This final article is available for use under the terms of the Creative Commons Attribution Non-Commercial 2.0 Licence; see http://bmjopen.bmj.com

For numbered affiliations see end of article.

Correspondence to Melissa Voigt Hansen; melis_vh@hotmail.com

\section{ABSTRACT}

Introduction: Breast cancer represents about onethird of all cancer diagnoses and accounts for about $15 \%$ of cancer deaths in women. Many of these patients experience depression, anxiety, sleep disturbances and cognitive dysfunction. This may adversely affect quality of life and also contribute to morbidity and mortality. Melatonin is a regulatory circadian hormone having, among others, a hypnotic and an antidepressive effect. It has very low toxicity and very few adverse effects compared with the more commonly used antidepressants and hypnotics.

Methods and analysis: The objective of this doubleblind, randomised, placebo-controlled trial is to investigate whether treatment with oral melatonin has a prophylactic or ameliorating effect on depressive symptoms, anxiety, sleep disturbances and cognitive dysfunction in women with breast cancer. Furthermore, the authors will examine whether a specific clock-gene, PER3, is correlated with an increased risk of depressive symptoms, sleep disturbances or cognitive dysfunction. The MELODY trial is a prospective double-blinded, randomised, placebo-controlled trial in which the authors intend to include 260 patients. The primary outcome is depressive symptoms measured by the Major Depression Inventory. The secondary outcomes are anxiety measured by a Visual Analogue Scale, total sleep time, sleep efficiency, sleep latency and periods awake measured by actigraphy and changes in cognitive function measured by a neuropsychological test battery. Tertiary outcomes are fatigue, pain, wellbeing and sleep quality/quantity measured by Visual Analogue Scale and sleep diary and sleepiness measured by the Karolinska Sleepiness Scale. The PER3 genotype is also to be determined in blood samples.

\section{ARTICLE SUMMARY}

This is a protocol article on the MELODY trial. The objective of this double-blind randomized, placebocontrolled trial is to investigate whether daily treatment with $6 \mathrm{mg}$ oral melatonin has a prophylactic or ameliorating effect on depressive symptoms, anxiety, sleep disturbances and cognitive dysfunction in women with breast cancer. Furthermore to examine whether a specific clock-gene PER3 is correlated with an increased risk of depressive symptoms, sleep disturbances or cognitive dysfunction.

\section{INTRODUCTION}

Breast cancer is the most common type of cancer among women worldwide with about 1.4 million new cases every year. ${ }^{1}$ Breast cancer accounts for $31 \%$ of the various cancer diagnoses in women and is responsible for $15 \%$ of deaths in women due to cancer. ${ }^{2}$ For Danish women, it is the most common type of cancer and the incidence is rising. ${ }^{3}$ The incidence rises towards the age of 65 and then the curve flattens out. ${ }^{3}$ Improvement of treatment has led to increasing 5-year survival, which is now $84 \%$ in Denmark ${ }^{4}$ and $89 \%$ in the USA. ${ }^{5}$ Now focus has turned to optimising quality of life because these patients may have a number of different psychological and physical symptoms, such as depression, anxiety, fatigue, cognitive dysfunction and sleep disturbances. ${ }^{6-12}$

\section{METHODS}

Study design and objectives

MELODY (The effect of MELatOnin on Depression, anxietY, cognitive function and 
sleep disturbances in breast cancer patients) is a prospective double-blinded, randomised, placebo-controlled trial in which we intend to include 260 patients undergoing surgery for breast cancer at Herlev University Hospital in Copenhagen, Denmark. If target sample size is not being adequately achieved, other centres/hospitals in Denmark will be invited to participate.

The objective is to investigate whether treatment with oral melatonin has a prophylactic or ameliorating effect on depressive symptoms, anxiety, sleep disturbances and cognitive dysfunction in women with breast cancer. Furthermore, we will examine whether a specific clockgene, PER3, is correlated with an increased risk of depressive symptoms, sleep disturbances or cognitive dysfunction.

Patients in the intervention group will receive $6 \mathrm{mg}$ oral melatonin daily $1 \mathrm{~h}$ before bedtime for 1 week preoperatively to 12 weeks postoperatively. Patients in the control group will receive placebo.

The melatonin/placebo will be supplied from Pharma Nord ApS (Vejle, Denmark), and the tablets (melatonin/ placebo) are physically identical.

\section{Study population}

Approximately 1 week preoperatively patients are individually assessed and screened for inclusion (table 1). This includes a Mini Mental State Examination, a neuropsychological test with the ISPOCD test battery ${ }^{13}$ and the
Major Depression Inventory (MDI). ${ }^{14-16}$ Hereafter, patients will on a daily basis fill out Visual Analogue Scales (VAS) regarding anxiety, fatigue, pain, general well-being and sleep, complete a sleep diary and fill out the Karolinska Sleepiness Scale (KSS). An Actigraph will be mounted on the wrist and worn continuously until 2 weeks postoperatively. Patients will be randomised to either $6 \mathrm{mg}$ melatonin or placebo. Patients will be instructed to take their medicine every evening at 21:00-22:00 and continue with this for 13 weeks. A blood sample will be collected for the analysis of PER3 genotype.

A visit is scheduled 2 weeks postoperatively where patients are tested with the ISPOCD test battery and the MDI. At this time, the Actigraph will be taken off.

During the last 10 weeks of the study, patients will be assessed with the MDI twice and every 2 weeks fill out VAS regarding anxiety, fatigue, pain, general well-being and sleep, complete a sleep diary and fill out the KSS.

At the final visit, 12 weeks postoperatively patients will be tested with the ISPOCD test battery and the MDI.

To ensure compliance and promote participant retention and follow-up, patients will throughout the whole study period of 13 weeks be contacted by telephone seven times to remind them to fill out VAS, sleep diary, KSS and MDI at appropriate times, to remind them to take their tablets daily, to ask about adverse reactions and to ask about diagnosis of depression since the last contact.

Table 1 Inclusion and exclusion criteria

\begin{tabular}{|c|c|}
\hline Inclusion criteria & Exclusion criteria \\
\hline $\begin{array}{l}\text { Women between } 30 \text { and } 75 \text { years } \\
\text { Lumpectomy or mastectomy } \\
\text { American Society of Anesthesiologists } \\
\text { (ASA) classes I-III } \\
\text { - No sign of depression on Major Depression } \\
\text { Inventory (MDI) } \\
\text { - Not pregnant }\end{array}$ & $\begin{array}{l}\text { Neoadjuvant chemotherapy } \\
\text { - Treatment with: } \\
\text { - Antithrombotic drug therapy (except } 75 \text { mg acetylsalicylic } \\
\text { acid daily) } \\
\text { - Monoaminoxidase (MAO) inhibitors } \\
\text { - Calcium channel blockers } \\
\text { - Rotor or Dubin-Johnson syndrome } \\
\text { Epilepsy } \\
\text { Known allergic reaction to melatonin } \\
\text { Known and treated sleep apnoea } \\
\text { Diabetes mellitus treated with insulin } \\
\text { Ongoing or previous medically treated depression or bipolar disorder } \\
\text { Known autoimmune diseases (systemic lupus erythematosus, } \\
\text { rheumatoid arthritis or multiple sclerosis) } \\
\text { Incompensated liver cirrhosis } \\
\text { Severe kidney disease (receiving dialysis) } \\
\text { Previous or other current cancer } \\
\text { Known medically treated sleep disorder (insomnia, restless legs, etc) } \\
\text { Shift work or night work } \\
\text { Daily intake of }>5 \text { units (1 unit = } 8 \text { g pure alcohol) } \\
\text { drugs of any kind, opioids, anxiolytics or hypnotics } \\
\text { Breast feeding } \\
\text { Preoperative Mini Mental State Examination score <24 }\end{array}$ \\
\hline
\end{tabular}


Criteria for discontinuing in the trial

During the trial, patients who experience serious peri- or postoperative complications/events causing unexpected morbidity or pain during the first postoperative days (ie, cardiopulmonary complications (myocardial infarction, serious arrhythmia, pulmonary oedema), thromboembolic complications (deep venous thrombosis, pulmonary embolism) and wound infection (with fever and elevated white blood cells and $\mathrm{C}$ reactive protein)), will be excluded. No further data will be collected on these patients after they are excluded; previously collected data will not be analysed, and the patients will not continue the trial medication.

The goal with medicine compliance is a minimum of $75 \%$ compliance in the first 3 weeks and $50 \%$ for the rest of the study period. Patients will be excluded if they at the visit 2 weeks postoperatively have not taken at least $75 \%$ of the study medication. No further data will be collected and the patients will not continue the trial medication. Patients who have not taken at least $50 \%$ of the trial medication at the last visit will not be analysed on the long-term effect variables. Patients will be instructed to bring all the study medication (open and closed blister packets) with them at every visit to control compliance.

All potential, included and randomised patients will be accounted for in a screening log, in an identification list, in the CONSORT trial profile and in a baseline data table.

\section{Randomisation}

Patients who have provided written and informed consent preceding inclusion and who meet all the inclusion criteria and none of the exclusion criteria are randomised to either melatonin $6 \mathrm{mg}$ or placebo. Inclusion and randomisation is done 1 week preoperatively.

The randomisation is based on blocks of six. The randomisation list is computer generated using dedicated software (http://www.randomization.com). To ensure that the randomisation list is not known to the investigator, this procedure is completed by the pharmacy who receives the medicine directly from Pharma Nord ApS. In case of dropouts leading to $<120$ patients in each group, the study will include new blocks of six patients to ensure randomisation and balance between the two groups.

\section{Data and adverse events}

Data are collected on individual paper case report forms (CRFs), and data will be stored for 15 years and then destroyed. Data from these CRFs will be transferred as double data entry to a database. In this database, patients are coded with a patient number and the database is saved on the hospitals computer server to ensure maximum security. Spot checks to validate data transfer from the CRFs to the electronic database will be completed by the Good Clinical Practice Unit.

Due to melatonins relative non-toxicity shown in both animal and human studies and due to the fact that prolonged treatment with melatonin or melatonin receptor agonists have not shown any serious adverse effects, no Data Monitoring Committee is initiated and no interim analyses have been planned in the course of the study.

Throughout the trial, both the sponsor/investigator, who informs the patient and the patient herself, will be blinded. A code breach will occur if an unexpected event arises in relation to the surgical procedure and/or the postoperative period where there is a reasonable probability of an adverse reaction. Unexpected events do not include procedure-related surgical/medical/anaesthetic complications. Code breach is possible without prior contact to sponsor/investigator. The risk of early trial termination is not existent.

The summary of product characteristics for melatonin will be used as a reference document. The following known, usual side effects $(1 \%-10 \%)$ and non-usual side effects $(0.1 \%-1 \%)$ will not be registered as adverse events: light headache, light nausea, dyspepsia, minor symptoms of sleepiness and light morning drowsiness. Furthermore, complications in relation to surgery will neither be registered as adverse events.

All adverse events will be registered and reported to the Danish Medicines Agency and the local ethics committee in the final report. All serious adverse events will be reported to the local ethics committee in an annual report together with a report on patient safety. All serious adverse reactions will be reported to the Danish Medicines Agency in an annual report together with a report on patient safety. The summary of product characteristics for melatonin will be used to judge whether a serious adverse reaction is expected/unexpected and thereby a possible sudden unexpected serious adverse reaction. The sponsor/investigator will make sure that all information about sudden unexpected serious adverse reactions, that are lethal or life threatening, will be registered and reported to the Danish Medicines Agency as soon as possible and at the latest 7 days after sponsor/investigator has received knowledge of such a reaction. At the latest 8 days after this reporting, sponsor/investigator will inform the Danish Medicines Agency of the follow-up. All other sudden unexpected serious adverse reactions will be reported to the Danish Medicines Agency at the latest 15 days after sponsor/investigator has gained knowledge of these. In these situations, the patient will be followed until the reaction has terminated-either via contact with the sponsor/investigator or via the outpatient clinic at the hospital.

\section{Melatonin}

Melatonin is a hormone that is produced at night in the corpus pineale in a rhythmical pattern and controlled by an endogenous clock in the suprachiasmatic nucleus of the hypothalamus. ${ }^{17}$ Its main function is to synchronise the circadian rhythm. ${ }^{17}$ Melatonin is mostly known for its role as a circadian hormone, but it also has known sedative, ${ }^{18} \quad{ }^{19}$ anxiolytic, ${ }^{18} \quad{ }^{19}$ analgesic, ${ }^{20} \quad{ }^{21}$ 
antihypertensive, ${ }^{22} 23$ non-inflammatory ${ }^{24}$ and oncostatic effects. ${ }^{25-27}$ Melatonin has a possible antidepressive effect ${ }^{28-34}$ probably based on its effect on the central circadian regulation ${ }^{35}$ and an effect on improving cognitive function. ${ }^{36}$ Figure 1 shows the complexity of the relationship between breast cancer and depression and the possible attack points of melatonin.

The secretion rhythm, fluctuations and levels of melatonin have been previously investigated with regard to surgery, depression and also breast cancer. After surgery, melatonin secretion has shown to be acutely disturbed $^{37}$ with a delay of secretion and reduced amplitude. $^{38} 39$ Various lines of evidence show that depressed patients exhibit disturbances in both the amplitude and the shape of the melatonin secretion rhythm, with some studies showing a low nocturnal melatonin secretion and others showing an increase in secretion. $^{35} \mathrm{~A}$ growing amount of evidence from prospective studies suggests an association between night work and breast cancer risk, most likely due to subsequent melatonin suppression. ${ }^{40}$

Melatonin is relatively non-toxic. ${ }^{41-43}$ Animal studies have shown that the maximum dose given in vivo, without any adverse effects or death, is $200 \mathrm{mg} / \mathrm{kg}$ for pregnant rats throughout the whole pregnancy and $800 \mathrm{mg} / \mathrm{kg}$ for mice. ${ }^{44}{ }^{45}$ The drug has been used in many clinical studies of both adults ${ }^{18-202241424647}$ and newborns ${ }^{48} 49$ without serious adverse effects. Doses of $1000 \mathrm{mg}$ daily for 1 month have been given, and the only reported adverse effect was drowsiness. ${ }^{41}$ In a recent systematic review, the most often reported side effects were headache, dizziness, nausea and drowsiness. ${ }^{50}$

\section{PER3 clock-gene}

Previous studies have shown that certain genes, called clock-genes, have a role in regulating circadian rhythms and sleep in humans. ${ }^{51} \mathrm{~A}$ coding region in the clockgene PER3, which is repeated in either 4 or 5 units, has been coupled to various phenotypical traits, A or B people, sleep diseases, ${ }^{52-54}$ affective disorders, ${ }^{55}{ }^{56}$ cognitive function after sleep deprivation, ${ }^{54} 57$ and in one study, ${ }^{58}$ a relationship was found between the $5 / 5 \mathrm{og}$ $4 / 5$ genotype of the PER3 gene and breast cancer. We would like to investigate whether sleep quality, cognitive function or depressive symptoms are correlated with any of these three PER3 genotypes.

\section{Ethics}

The study will be performed in agreement with the Helsinki II declaration and law 503 of 1992 about the Scientific Ethics Committee System and is approved by the local ethics committee (H-4-2011-007). The study has also been approved by the Danish Medicines Agency (EudraCT nr. 2010-022460-12) and the Danish Data Protection Agency (2007-58-0015/HEH.750.89-12). The project is registered on http://www.clinicaltrials.gov as recommended by the International Committee of Medical Journal Editors-clinicaltrials.gov identifier: NCT01355523. The Good Clinical Practice Unit at Copenhagen University will oversee the trial and conduct trial audit periodically.

All authors will have direct access to data during and after the trial. Furthermore, the sponsor/investigator will allow direct access to source data/documents, including patient charts, at monitoring, audit and/or inspection from the Danish Medicines Agency, the Good Clinical Practice Unit or from health authorities from other countries.

\section{EFFECT PARAMETERS}

\section{Major Depression Inventory}

The primary, secondary and tertiary effect parameters of the trial can be seen in table 2. Major Depression Inventory (MDI) is a self-rating scale including 12 questions. The questionnaire is already well documented in a Danish population. ${ }^{14}$ The questions cover the 10 ICD-10 questions for depression, and the symptoms are identical with the DSM-IV major depression diagnosis apart from one symptom, low self-esteem (question 4), which in DSM-IV is incorporated in the question about guilt (question 5). The MDI includes 10 items, where
Figure 1 The relationship between breast cancer and depression. Modified after Fann et $a l^{6}$

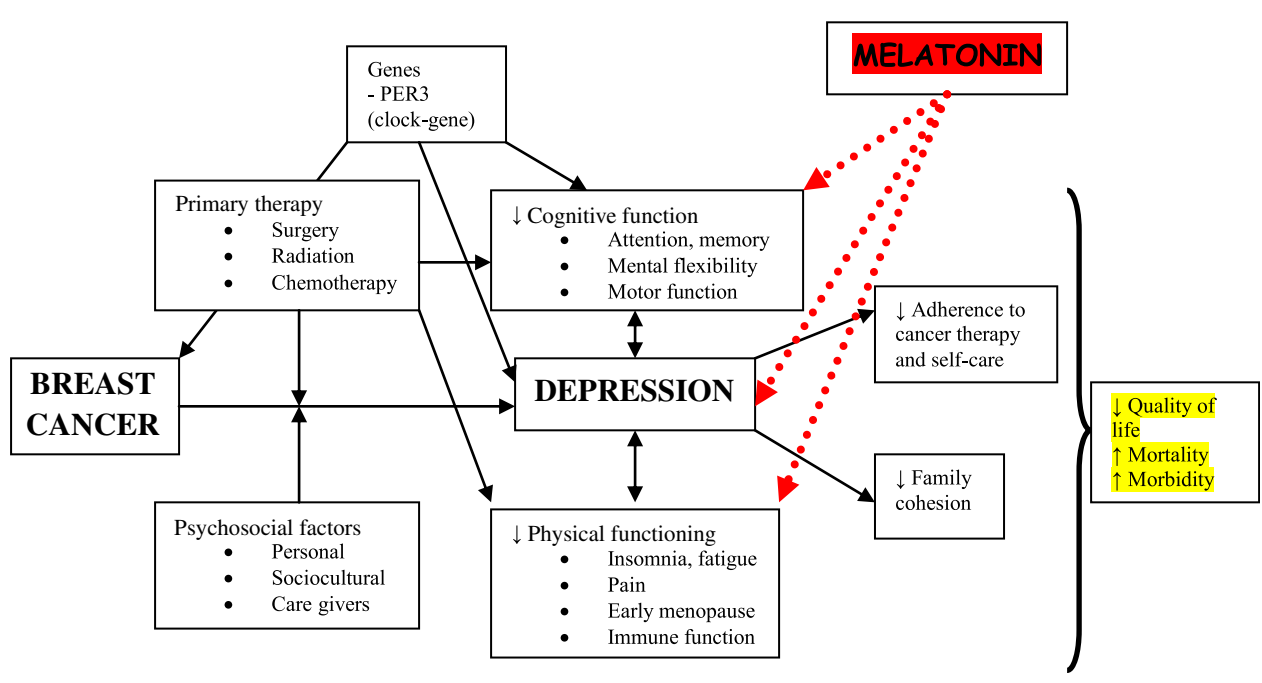




\begin{tabular}{lll} 
Table 2 Effect parameters & & \\
\hline Primary effect parameter & Secondary effect parameters & Tertiary effect parameters \\
\hline Major Depression & Anxiety measured by Visual Analogue & Fatigue, pain, well-being and sleep \\
Inventory & Scale (VAS) & quality/quantity measured by VAS \\
& Total sleep time, sleep efficiency, sleep & Sleep diary \\
& latency and periods awake measured by & Sleepiness measured by the Karolinska \\
& actigraphy & Sleepiness Scale \\
& Changes in cognitive function measured & \\
& by a neuropsychological test battery & \\
& PER3 genotype correlated with sleep, \\
& cognitive function and depressive symptoms & \\
\hline
\end{tabular}

items 8 and 10 are divided into two sub-questions a and b. For items 8 and 10, the highest score of questions $\mathrm{a}$ and $\mathrm{b}$ is included. The individual items are measured on a 6-point Likert scale with graduations depending on the extent of the symptom the last 14 days, 0 (the symptom has not been present) till 5 (the symptom has been present continuously).

The MDI has a dual function. It can be used as a diagnostic tool where it can, by algorithms, lead to either DSM-IV or ICD-10 categories of 'major' or 'moderate to severe depression'. An acceptable sensitivity and specificity for the diagnosis of depression according to ICD-10 and DSM-III/DSM-IV has previously been found. ${ }^{15}$ The MDI can also be used as a measuring instrument to indicate the severity of the depression. Thus, the MDI correlates with the Hamiltons Depressions Scale (HAM-D). ${ }^{16}$

\section{Actigraphy}

Actigraphy is a well-known, non-invasive method to objectively measure sleep. Using an actigraph, activity levels are registered by a wrist-worn mini-computer. This method which does not disturb the patients' sleep has been used for many years ${ }^{59}$ and also in the postoperative setting. ${ }^{60}$ It has been shown that actigraphy has a high sensitivity and specificity for detecting sleep start, sleep periods and awakenings. ${ }^{59}$ The gold standard for measuring sleep is polysomnography. Actigraphy has a high specificity for detecting whether the patient is asleep or awake but cannot differentiate between sleep stages and score REM sleep.

An actigraph measures small accelerations with a piezoelectrode and stores this in an internal memory. Data can be recorded via different modalities, and we will be using the zero crossing method, where all accelerations $(>0.1 \mathrm{G})$, which cross a certain threshold $(0$ or very close to 0 ), will be detected. The sleep analysis will be performed by dedicated software (Action4 software; Ambulatory Monitoring Inc., New York, New York, USA) by using the Cole-Kripke algorithm. ${ }^{61}$ Data will be reported as total sleep time per period, sleep efficiency, sleep ratio, number of awakenings and duration of awakenings. The method is validated and has been used previously to measure sleep in patients with breast cancer before, during and after surgery. ${ }^{62-65}$

\section{The ISPOCD neuropsychological test battery}

The cognitive function of the patients will be tested preoperatively and at 2 weeks and 3 months postoperatively. The test battery consists of four validated tests: the Visual Verbal Learning Test, the Stroop ColourWord Test, the Letter-Digit Coding Test and the Concept Shifting Task.

The test battery takes approximately $45 \mathrm{~min}$ to complete and has been used previously in the large multicenter ISPOCD trial. ${ }^{13}$

\section{Anxiety and sleep quality measurements}

A subjective feeling of anxiety will be registered on a VAS going from 'no anxiety' to 'worst possible anxiety'. Measurements will take place daily for the first 3 weeks of the study and every 2 weeks for the last 10 weeks.

Subjective sleep quality will be registered on a VAS going from 'best possible sleep' equivalent to $0 \mathrm{~mm}$ to 'worst possible sleep' equivalent to $100 \mathrm{~mm}$. Patients will also fill out VAS regarding general well-being, fatigue and pain. Measurements will take place at the same time as for anxiety.

Furthermore, a sleep diary, recording sleep time and awakening time, will be completed daily for the first 3 weeks of the study and thereafter every 14 days. Patients will at the same time periods complete the KSS, which is used to quantify levels of sleepiness. KSS is a 9-point scale from 1 (very awake) to 9 (very sleepy), where a score of 7 or more reflects pathological sleepiness. ${ }^{66}$

\section{Other collected data}

Age, weight, height, menopausal status, educational level, cohabitation status, work market affiliation, household income, number of children/number of children living at home, smoking habits, American Society of Anesthesiologists (ASA) class, duration of surgery, the size of the incision, consumption of analgesics postoperatively and which postoperative oncological treatment each patient receives after surgery.

\section{STATISTICAL ANALYSIS AND SAMPLE SIZE CALCULATION}

The sample size estimation is based on a conservative estimate of the incidence of depression of $30 \%$ in breast cancer patients ${ }^{7}$ with a reduction to $15 \%$ with melatonin treatment. With a power of $80 \%$, a risk of type I error of 
$5 \%$ and a risk of type II error of $20 \%$, we should include 120 patients in each group receiving melatonin or placebo. We have chosen to include 130 patients in each group. Statistical analyses will be done using SPSS V.18.0.

Regarding our primary outcome mean MDI total scores and prevalences of ICD-10 mild, moderate and severe depression will be calculated for both samples. Normality of the data will be tested by one sample Kolmogorov-Smirnov test and parametric or non-parametric statistics will be used accordingly. The two groups will be compared by Fisher's exact test for the primary outcome. Paired Student t test or Wilcoxon test will be used for intragroup comparisons and unpaired Student t test or Mann-Whitney's test for intergroup comparisons. For repeated measures, Friedman test or an analysis of variance will be used when appropriate.

For comparing anxiety by VAS and sleep architecture (objective data from the actigraph), we will do intergroup comparisons with Mann-Whitney's test and intragroup comparisons using the Wilcoxon signed-rank test.

For analysing postoperative cognitive dysfunction (POCD) in the two groups, we will use $2 \times 2$ tables and a Fisher's exact test. Patients will be defined as having POCD if two of the seven Z-scores in individual test or the combined Z-score are $\geq 1.96 .{ }^{13}$ Analysis of variance will be used to analyse the two groups and the specific Zscores for the seven subtests and the combined Z-scores. A Bonferroni correction will be made when performing multiple comparisons.

For analyses of correlation between PER3 genotype and sleep, cognitive function and depressive symptoms, a logistic regression analysis will be used. For the subjective parameters fatigue, pain, general well-being and sleep quality/quantity measured by VAS and sleepiness by KSS, we will do intergroup comparisons with the Mann-Whitney test and intragroup comparisons using the Wilcoxon signed-rank test. We plan to do intentionto-treat as well as per protocol analyses. In general, $\mathrm{p}<0.05$ will be considered statistically significant.

\section{DISCUSSION}

There is a complex relationship between depression and breast cancer with influence from various factors (figure 1). Due to the high frequencies of depression, anxiety, sleep disturbances and cognitive dysfunction in patients with breast cancer, a high interest is found in preventing these co-morbid symptoms.

Depression is both underdiagnosed and undertreated in many cancer patients, ${ }^{1167}$ especially those with breast cancer. ${ }^{68}$ The overall rate of depression in patients with breast cancer is higher than in most cancers. This is most likely because menopause, either naturally occurring or premature due to the effects of chemotherapy and/or anti-hormone treatment, and oestrogen decline are related to depression. ${ }^{6}$ It has been shown that up to $50 \%$ of patients with breast cancer may experience depression and/or anxiety within the first year of diagnosis. ${ }^{7}$
Concomitant breast cancer and depression is associated with higher mortality and morbidity ${ }^{67}{ }^{69-72}$ and also lower patient satisfaction ${ }^{73}$ and compliance to adjuvant therapy ${ }^{74}$ and general medical treatment. ${ }^{75}$ Even a year after surgery, many women still deal with an anxiety problem $^{76}$ and about $15 \%$ are still depressed. ${ }^{7}$

Studies have shown that treating anxiety and depression in these patients with breast cancer improves their quality of life, leads to a higher completion of adjuvant therapy and extends their lifetime. ${ }^{6877} 78$ Therefore, it is important to optimise the treatment of these symptoms.

A number of randomised, controlled trials have examined the efficacy of antidepressants compared with placebo in patients with breast cancer. ${ }^{78-85} \mathrm{~A}$ high number of dropouts due to side effects related to the antidepressant treatment have also rendered such trials difficult to complete. ${ }^{79} 84{ }^{86}$ Furthermore, recent evidence indicates that some selective serotonin reuptake inhibitor antidepressants may reduce tamoxifen's effectiveness and are associated with an increased risk of mortality. ${ }^{87} 88$

Sleep disturbances are a frequent problem in cancer patients. ${ }^{89} 90$ Compared with other types of cancer, breast cancer is associated with an exceptionally high rate of reduced sleep quality ${ }^{10}{ }^{89}$ which can be found even many years after end of treatment. ${ }^{8}$ The estimated prevalence of sleep problems among patients with breast cancer is between $38 \%$ and $61 \%,{ }^{10} 899192$ and it may reduce quality of life in this group of patients. ${ }^{91}{ }^{93}$ About $30 \%$ of patients with breast cancer take hypnotics ${ }^{10} 8992$ leading to a potential dependency problem and it is therefore important to focus on treatments with less adverse effects.

The sleep disturbances can be due to a variety of factors, both physical and psychological, which all have a mutual influence on each other. Among the psychological factors, depression and anxiety are well known, and these patients also exhibit a change in sleep architecture. ${ }^{94}$ In general, depressed patients display sleep abnormalities such as difficulties falling asleep and staying asleep, lose of slow-wave-sleep and changed REM sleep. ${ }^{95}$ Pain and hot flushes are examples of the physical factors. ${ }^{8} 9192$

Overall, it is difficult to conclude whether sleep disturbances are a precursor or a sequelae of depression. Various studies in healthy individuals have shown a causal relationship between sleep disturbances and the following development of depression. ${ }^{96}{ }^{97}$ More specifically for patients with breast cancer, a circadian rhythm disruption has been associated with depression, fatigue and pain. ${ }^{62} 636598$ Altogether, there is a complicated relationship between circadian disturbances, sleep and $\operatorname{mood},{ }^{35}$ and this is especially prevalent in patients with breast cancer. ${ }^{99}$

Disturbances of cognitive function are a prevalent phenomenon in patients with breast cancer and can influence the general quality of life in this group of patients. ${ }^{9}{ }^{12}$ Studies have suggested that the cancer per 
se and/or the treatment with surgery, radiation, chemotherapy and hormone therapy or genetics can be contributing factors in the development of cognitive disturbances. ${ }^{100101}$ POCD is characterised by a deterioration in memory, concentration and information assessment after surgery. ${ }^{13}$

In other settings, some studies have shown that melatonin can attenuate cognitive dysfunction, ${ }^{36102103}$ and this mechanism together with the general improvement of sleep could be beneficial on cognitive disturbances in this specific group of patients. Since there is no specific knowledge on this topic with regard to breast cancer, it is necessary to investigate whether the development of cognitive problems can be prevented by melatonin treatment.

In conclusion, we hope, with this project, to decrease the occurrence of depression, anxiety, sleep disturbances and cognitive dysfunction in patients with breast cancer and in a larger perspective reduce morbidity and mortality and improve quality of life for these patients. With regard to genetics, this project could lead to the possibility of being able to detect women with a higher risk of developing the above mentioned problems and then give indication for selective prophylactic treatment. The diversity of melatonin's physiological functions and treatment effects are continuously being investigated in both animal and human studies. To date, the effect of melatonin in a breast cancer population with the abovementioned indications has not yet been studied.

\section{Author affiliations}

${ }^{1}$ Department of Surgery, Herlev Hospital, University of Copenhagen, Copenhagen, Denmark

${ }^{2}$ Psychiatric Center Copenhagen, Rigshospitalet, University of Copenhagen, Copenhagen, Denmark

${ }^{3}$ Department of Anaesthesia, Centre of Head and Orthopaedics, University of Copenhagen, Copenhagen, Denmark

${ }^{4}$ Department of Breast Surgery, Herlev Hospital, University of Copenhagen, Copenhagen, Denmark

Funding This work was supported by grants from the University of Copenhagen, the Aase and Ejnar Danielsens Foundation, the A P Møller Foundation for the Advancement of Medical Science, the Else and Mogens Wedell Wedellborgs Foundation, the Beckett Foundation, the Hede Nielsen Family Foundation, the Dagmar Marshalls Foundation and Manufacturer Einar Willumsen's Memorial Scholarship. These above-mentioned funders have had no influence on the study design, will have no influence on collection, management, analysis and interpretation of data, writing of the report or the decision to submit the report for publication. All these activities are done by the authors. Pharma Nord provided the melatonin and placebo tablets but had no influence on the study design and will have no influence on the interpretation of results.

\section{Competing interests None.}

Contributors All authors have participated in making substantial contributions to conception and design, drafting the article or revising it critically for important intellectual content and all authors have approved the final version to be published.

Provenance and peer review Not commissioned; externally peer reviewed.

\section{REFERENCES}

1. http://globocan.iarc.fr/factsheets/cancers/breast.asp (accessed Nov 2011).
2. Greenlee RT, Hill-Harmon MB, Murray T, et al. Cancer statistics, 2001. CA Cancer J Clin 2001;51:15-36.

3. http://www.sst.dk/publ/Publ2009/DOKU/cancerreg/ cancerregisteret_2008.pdf (accessed Nov 2011).

4. http://www.sst.dk/publ/Publ2010/DOKU/Sygehusbaseret Overlevelse/SygehuspatientersOverlevelse1997-2008.pdf (accessed Nov 2011).

5. http://www.cancer.org/acs/groups/content/@epidemiologysurveilance/ documents/document/acspc-030975.pdf (accessed Nov 2011).

6. Fann JR, Thomas-Rich AM, Katon WJ, et al. Major depression after breast cancer: a review of epidemiology and treatment. Gen Hosp Psychiatry 2008;30:112-26.

7. Burgess C, Cornelius V, Love S, et al. Depression and anxiety in women with early breast cancer: five year observational cohort study. BMJ 2005;330:702-5.

8. Otte JL, Carpenter JS, Russell KM, et al. Prevalence, severity, and correlates of sleep-wake disturbances in long-term breast cancer survivors. J Pain Symptom Manage 2010;39:535-47.

9. Debess J, Riis JO, Pedersen L, et al. Cognitive function and quality of life after surgery for early breast cancer in North Jutland, Denmark. Acta Oncol 2009;48:532-40.

10. Savard J, Simard S, Blanchet J, et al. Prevalence, clinical characteristics, and risk factors for insomnia in the context of breast cancer. Sleep 2001;24:583-90.

11. Massie MJ. Prevalence of depression in patients with cancer. J Nat/ Cancer Inst Monogr 2004;32:57-71.

12. Schou I, Ekeberg O, Sandvik L, et al. Multiple predictors of healthrelated quality of life in early stage breast cancer. Data from a year follow-up study compared with the general population. Qual Life Res 2005;14:1813-23.

13. Moller JT, Cluitmans P, Rasmussen LS, et al. Long-term postoperative cognitive dysfunction in the elderly ISPOCD1 study. ISPOCD investigators. International Study of Post-Operative Cognitive Dysfunction. Lancet 1998;351:857-61.

14. Olsen LR, Mortensen EL, Bech P. Prevalence of major depression and stress indicators in the Danish general population. Acta Psychiatr Scand 2004;109:96-103.

15. Bech P, Rasmussen NA, Olsen LR, et al. The sensitivity and specificity of the Major Depression Inventory, using the Present State Examination as the index of diagnostic validity. J Affect Disord 2001;66:159-64.

16. Olsen LR, Jensen DV, Noerholm V, et al. The internal and external validity of the Major Depression Inventory in measuring severity of depressive states. Psychol Med 2003;33:351-6.

17. Claustrat B, Brun J, Chazot G. The basic physiology and pathophysiology of melatonin. Sleep Med Rev 2005;9:11-24.

18. Acil M, Basgul E, Celiker V, et al. Perioperative effects of melatonin and midazolam premedication on sedation, orientation, anxiety scores and psychomotor performance. Eur $J$ Anaesthesiol 2004:21:553-7.

19. Naguib M, Samarkandi AH. Premedication with melatonin: a doubleblind, placebo-controlled comparison with midazolam. $\mathrm{Br} J$ Anaesth 1999;82:875-80.

20. Caumo W, Torres F, Moreira NL Jr, et al. The clinical impact of preoperative melatonin on postoperative outcomes in patients undergoing abdominal hysterectomy. Anesth Analg 2007; 105:1263-71.

21. Srinivasan V, Pandi-Perumal SR, Spence DW, et al. Potential use of melatonergic drugs in analgesia: mechanisms of action. Brain Res Bull 2010;81:362-71.

22. Cagnacci A, Cannoletta M, Renzi A, et al. Prolonged melatonin administration decreases nocturnal blood pressure in women. $A m \mathrm{~J}$ Hypertens 2005;18:1614-18.

23. Kitajima T, Kanbayashi T, Saitoh $\mathrm{Y}$, et al. The effects of oral melatonin on the autonomic function in healthy subjects. Psychiatry Clin Neurosci 2001;55:299-300.

24. Maestroni GJ. The immunotherapeutic potential of melatonin. Expert Opin Investig Drugs 2001;10:467-76.

25. Vijayalaxmi B, Thomas CR Jr, Reiter RJ, et al. Melatonin: from basic research to cancer treatment clinics. J Clin Oncol 2002;20:2575-601.

26. Reiter RJ. Mechanisms of cancer inhibition by melatonin. $J$ Pineal Res 2004;37:213-14.

27. Grant SG, Melan MA, Latimer JJ, et al. Melatonin and breast cancer: cellular mechanisms, clinical studies and future perspectives. Expert Rev Mol Med 2009;11:e5.

28. Bellipanni G, Di MF, Blasi F, et al. Effects of melatonin in perimenopausal and menopausal women: our personal experience. Ann N Y Acad Sci 2005;1057:393-402.

29. Kopp C, Vogel E, Rettori MC, et al. The effects of melatonin on the behavioural disturbances induced by chronic mild stress in $\mathrm{C} 3 \mathrm{H} / \mathrm{He}$ mice. Behav Pharmacol 1999;10:73-83. 
30. Hickie IB, Rogers NL. Novel melatonin-based therapies: potential advances in the treatment of major depression. Lancet 2011;378:621-31.

31. Serfaty MA, Osborne D, Buszewicz MJ, et al. A randomized doubleblind placebo-controlled trial of treatment as usual plus exogenous slow-release melatonin $(6 \mathrm{mg})$ or placebo for sleep disturbance and depressed mood. Int Clin Psychopharmacol 2010;25:132-42.

32. G Spadoni, A Bedini, S Rivara, et al. Melatonin receptor agonists: new options for insomnia and depression treatment. CNS Neurosci Ther. Published Online First: 15 October 2010. doi:10.1111/j.17555949.2010.00197.x

33. Garzon C, Guerrero JM, Aramburu O, et al. Effect of melatonin administration on sleep, behavioral disorders and hypnotic drug discontinuation in the elderly: a randomized, double-blind, placebocontrolled study. Aging Clin Exp Res 2009;21:38-42.

34. Rahman SA, Kayumov L, Shapiro CM. Antidepressant action of melatonin in the treatment of Delayed Sleep Phase Syndrome. Sleep Med 2010;11:131-6.

35. Srinivasan V, Pandi-Perumal SR, Trakht I, et al. Pathophysiology of depression: role of sleep and the melatonergic system. Psychiatry Res 2009;165:201-14

36. Furio AM, Brusco LI, Cardinali DP. Possible therapeutic value of melatonin in mild cognitive impairment: a retrospective study. $J$ Pineal Res 2007;43:404-9.

37. Ram E, Vishne TH, Weinstein T, et al. General anesthesia for surgery influences melatonin and cortisol levels. World J Surg 2005;29:826-9

38. Karkela J, Vakkuri O, Kaukinen S, et al. The influence of anaesthesia and surgery on the circadian rhythm of melatonin. Acta Anaesthesiol Scand 2002;46:30-6.

39. Gogenur I, Middleton B, Kristiansen VB, et al. Disturbances in melatonin and core body temperature circadian rhythms after minimal invasive surgery. Acta Anaesthesiol Scand 2007;51:1099-106

40. Megdal SP, Kroenke $\mathrm{CH}$, Laden F, et al. Night work and breast cancer risk: a systematic review and meta-analysis. Eur J Cancer 2005;41:2023-32.

41. Nordlund JJ, Lerner AB. The effects of oral melatonin on skin color and on the release of pituitary hormones. J Clin Endocrinol Metab 1977;45:768-74.

42. Nickkholgh $A$, Schneider $H$, Sobirey $M$, et al. The use of high-dose melatonin in liver resection is safe: first clinical experience. J Pineal Res 2011;50:381-8.

43. Seabra ML, Bignotto M, Pinto LR Jr, et al. Randomized, double-blind clinical trial, controlled with placebo, of the toxicology of chronic melatonin treatment. J Pineal Res 2000;29:193-200.

44. Jahnke G, Marr M, Myers C, et al. Maternal and developmental toxicity evaluation of melatonin administered orally to pregnant Sprague-Dawley rats. Toxicol Sci 1999;50:271-9.

45. Barchas J, DaCosta F, Spector S. Acute pharmacology of melatonin. Nature 1967;214:919-20.

46. Shaw KM, Stern GM, Sandler M. Melatonin and parkinsonism. Lancet 1973;1:271.

47. Zhdanova IV, Wurtman RJ, Morabito C, et al. Effects of low oral doses of melatonin, given 2-4 hours before habitual bedtime, on sleep in normal young humans. Sleep 1996;19:423-31.

48. Gitto E, Romeo C, Reiter RJ, et al. Melatonin reduces oxidative stress in surgical neonates. J Pediatr Surg 2004;39:184-9.

49. Gitto E, Karbownik M, Reiter RJ, et al. Effects of melatonin treatment in septic newborns. Pediatr Res 2001;50:756-60.

50. Buscemi N, Vandermeer B, Hooton N, et al. Efficacy and safety of exogenous melatonin for secondary sleep disorders and sleep disorders accompanying sleep restriction: meta-analysis. BMJ 2006;332:385-93.

51. Dijk DJ, Archer SN. PERIOD3, circadian phenotypes, and sleep homeostasis. Sleep Med Rev 2010;14:151-60.

52. Archer SN, Robilliard DL, Skene DJ, et al. A length polymorphism in the circadian clock gene Per3 is linked to delayed sleep phase syndrome and extreme diurnal preference. Sleep 2003;26:413-15.

53. Johansson C, Willeit M, Smedh C, et al. Circadian clock-related polymorphisms in seasonal affective disorder and their relevance to diurnal preference. Neuropsychopharmacology 2003;28:734-9.

54. Viola AU, Archer SN, James LM, et al. PER3 polymorphism predicts sleep structure and waking performance. Curr Biol 2007;17:613-18.

55. Nievergelt CM, Kripke DF, Barrett TB, et al. Suggestive evidence for association of the circadian genes PERIOD3 and ARNTL with bipolar disorder. Am J Med Genet B Neuropsychiatr Genet 2006;141B:234-41.

56. Artioli $\mathrm{P}$, Lorenzi $\mathrm{C}$, Pirovano $\mathrm{A}$, et al. How do genes exert their role? Period 3 gene variants and possible influences on mood disorder phenotypes. Eur Neuropsychopharmacol 2007;17:587-94.
57. Groeger JA, Viola AU, Lo JC, et al. Early morning executive functioning during sleep deprivation is compromised by a PERIOD3 polymorphism. Sleep 2008;31:1159-67.

58. Zhu Y, Brown HN, Zhang $\mathrm{Y}$, et al. Period3 structural variation: a circadian biomarker associated with breast cancer in young women. Cancer Epidemiol Biomarkers Prev 2005;14:268-70.

59. Ancoli-Israel S, Cole R, Alessi C, et al. The role of actigraphy in the study of sleep and circadian rhythms. Sleep 2003;26: 342-92.

60. Bisgaard T, Kjaersgaard M, Bernhard A, et al. Computerized monitoring of physical activity and sleep in postoperative abdominal surgery patients. J Clin Monit Comput 1999;15:1-8.

61. Cole RJ, Kripke DF, Gruen W, et al. Automatic sleep/wake identification from wrist activity. Sleep 1992;15:461-9.

62. Berger AM, Wielgus K, Hertzog M, et al. Patterns of circadian activity rhythms and their relationships with fatigue and anxiety/depression in women treated with breast cancer adjuvant chemotherapy. Support Care Cancer 2010;18:105-14

63. Wright $\mathrm{CE}$, Bovbjerg $\mathrm{DH}$, Montgomery $\mathrm{GH}$, et al. Disrupted sleep the night before breast surgery is associated with increased postoperative pain. J Pain Symptom Manage 2009;37:352-62.

64. Ancoli-Israel S, Liu L, Marler MR, et al. Fatigue, sleep, and circadian rhythms prior to chemotherapy for breast cancer. Support Care Cancer 2006;14:201-9.

65. Roscoe JA, Morrow GR, Hickok JT, et al. Temporal interrelationships among fatigue, circadian rhythm and depression in breast cancer patients undergoing chemotherapy treatment. Support Care Cancer 2002;10:329-36.

66. Akerstedt T, Gillberg M. Subjective and objective sleepiness in the active individual. Int J Neurosci 1990;52:29-37.

67. Caplette-Gingras A, Savard J. Depression in women with metastatic breast cancer: a review of the literature. Palliat Support Care 2008;6:377-87.

68. Somerset W, Stout SC, Miller $\mathrm{AH}$, et al. Breast cancer and depression. Oncology 2004;18:1021-34.

69. Hjerl K, Andersen EW, Keiding N, et al. Depression as a prognostic factor for breast cancer mortality. Psychosomatics 2003;44:24-30.

70. Watson M, Haviland JS, Greer S, et al. Influence of psychological response on survival in breast cancer: a population-based cohort study. Lancet 1999;354:1331-6.

71. Satin JR, Linden W, Phillips MJ. Depression as a predictor of disease progression and mortality in cancer patients: a metaanalysis. Cancer 2009;115:5349-61.

72. Abrams TE, Vaughan-Sarrazin M, Rosenthal GE. Influence of psychiatric comorbidity on surgical mortality. Arch Surg 2010;145:947-53.

73. Bui QU, Ostir GV, Kuo YF, et al. Relationship of depression to patient satisfaction: findings from the barriers to breast cancer study Breast Cancer Res Treat 2005;89:23-8.

74. Colleoni M, Mandala M, Peruzzotti G, et al. Depression and degree of acceptance of adjuvant cytotoxic drugs. Lancet 2000;356:1326-7.

75. DiMatteo MR, Lepper HS, Croghan TW. Depression is a risk factor for noncompliance with medical treatment: meta-analysis of the effects of anxiety and depression on patient adherence. Arch Intern Med 2000;160:2101-7.

76. Hartl K, Schennach R, Muller M, et al. Quality of life, anxiety, and oncological factors: a follow-up study of breast cancer patients. Psychosomatics 2010;51:112-23.

77. Giese-Davis J, Collie K, Rancourt KM, et al. Decrease in depression symptoms is associated with longer survival in patients with metastatic breast cancer: a secondary analysis. J Clin Oncol 2011;29:413-20.

78. Navari RM, Brenner MC, Wilson MN. Treatment of depressive symptoms in patients with early stage breast cancer undergoing adjuvant therapy. Breast Cancer Res Treat 2008;112:197-201.

79. Pezzella G, Moslinger-Gehmayr R, Contu A. Treatment of depression in patients with breast cancer: a comparison between paroxetine and amitriptyline. Breast Cancer Res Treat 2001;70:1-10.

80. Roscoe JA, Morrow GR, Hickok JT, et al. Effect of paroxetine hydrochloride (Paxil) on fatigue and depression in breast cancer patients receiving chemotherapy. Breast Cancer Res Treat 2005;89:243-9.

81. van HK, Zivkov M. Pharmacological treatment of depression in cancer patients. A placebo-controlled study of mianserin. $\mathrm{Br} \mathrm{J}$ Psychiatry 1996;169:440-3.

82. Musselman DL, Somerset WI, Guo Y, et al. A double-blind, multicenter, parallel-group study of paroxetine, desipramine, or placebo in breast cancer patients (stages I, II, III, and IV) with major depression. J Clin Psychiatry 2006;67:288-96. 
83. Grassi L, Biancosino B, Marmai L, et al. Effect of reboxetine on major depressive disorder in breast cancer patients: an open-label study. J Clin Psychiatry 2004;65:515-20.

84. Fisch MJ, Loehrer PJ, Kristeller J, et al. Fluoxetine versus placebo in advanced cancer outpatients: a double-blinded trial of the Hoosier Oncology Group. J Clin Oncol 2003;21:1937-43.

85. Morrow GR, Hickok JT, Roscoe JA, et al. Differential effects of paroxetine on fatigue and depression: a randomized, double-blind trial from the University of Rochester Cancer Center Community Clinical Oncology Program. J Clin Oncol 2003;21:4635-41.

86. Pirl WF, Roth AJ. Diagnosis and treatment of depression in cancer patients. Oncology 1999;13:1293-301.

87. Kelly CM, Juurlink DN, Gomes T, et al. Selective serotonin reuptake inhibitors and breast cancer mortality in women receiving tamoxifen: a population based cohort study. BMJ 2010;340:c693.

88. Desmarais JE, Looper KJ. Interactions between tamoxifen and antidepressants via cytochrome P450 2D6. J Clin Psychiatry 2009;70:1688-97.

89. Davidson JR, MacLean AW, Brundage MD, et al. Sleep disturbance in cancer patients. Soc Sci Med 2002;54:1309-21.

90. Savard J, Morin CM. Insomnia in the context of cancer: a review of a neglected problem. J Clin Oncol 2001;19:895-908.

91. Fortner BV, Stepanski EJ, Wang SC, et al. Sleep and quality of life in breast cancer patients. J Pain Symptom Manage 2002;24:471-80.

92. Koopman C, Nouriani B, Erickson V, et al. Sleep disturbances in women with metastatic breast cancer. Breast $J$ 2002;8:362-70.

93. Dow $\mathrm{KH}$, Ferrell BR, Leigh $\mathrm{S}$, et al. An evaluation of the quality of life among long-term survivors of breast cancer. Breast Cancer Res Treat 1996;39:261-73.
94. Morin CM, Ware JC. Sleep and psychopathology. Appl Prev Psychol 1996;5:211-24.

95. Benca RM, Okawa M, Uchiyama M, et al. Sleep and mood disorders. Sleep Med Rev 1997;1:45-56.

96. Breslau N, Roth T, Rosenthal L, et al. Sleep disturbance and psychiatric disorders: a longitudinal epidemiological study of young adults. Biol Psychiatry 1996;39:411-18.

97. Livingston G, Blizard B, Mann A. Does sleep disturbance predict depression in elderly people? A study in inner London. $\mathrm{Br} J \mathrm{Gen}$ Pract 1993;43:445-8.

98. Ancoli-Israel S, Moore PJ, Jones V. The relationship between fatigue and sleep in cancer patients: a review. Eur J Cancer Care (Engl) 2001;10:245-55.

99. Palesh OG, Collie K, Batiuchok D, et al. A longitudinal study of depression, pain, and stress as predictors of sleep disturbance among women with metastatic breast cancer. Biol Psychol 2007;75:37-44.

100. Wefel JS, Lenzi R, Theriault R, et al. 'Chemobrain' in breast carcinoma?: a prologue. Cancer 2004;101:466-75.

101. Jim HS, Donovan KA, Small BJ, et al. Cognitive functioning in breast cancer survivors: a controlled comparison. Cancer 2009;115:1776-83.

102. Manda K, Reiter RJ. Melatonin maintains adult hippocampal neurogenesis and cognitive functions after irradiation. Prog Neurobiol 2010;90:60-8.

103. Sharma AK, Mehta AK, Rathor N, et al. Melatonin attenuates cognitive dysfunction and reduces neural oxidative stress induced by phosphamidon. Fundam Clin Pharmacol. Published Online First: 26 July 2011. doi:10.1111/j.1472-8206.2011.00977.x 